\title{
Skin Rash Can Be a Useful Marker for Afatinib Efficacy
}

\author{
SHINGO NASU ${ }^{1}$, HIDEKAZU SUZUKI ${ }^{1}$, TAKAYUKI SHIROYAMA ${ }^{1}$, AYAKO TANAKA $^{1}$, KAORI IWATA ${ }^{2}$, \\ NORIKO RYOTA ${ }^{2}$, YUKI UEDA ${ }^{3}$, SO TAKATA ${ }^{1}$, KENTARO MASUHIRO $^{1}$, SATOMU MORITA ${ }^{1}$, \\ NAOKO MORISHITA $^{1}$, NORIO OKAMOTO ${ }^{1}$ and TOMONORI HIRASHIMA ${ }^{1}$ \\ Departments of ${ }^{1}$ Thoracic Oncology, ${ }^{2}$ Nursing, and ${ }^{3}$ Pharmacy, \\ Osaka Prefectural Hospital Organization Osaka Habikino Medical Center, Osaka, Japan
}

\begin{abstract}
Background/Aim: Although afatinib has a strong efficacy, it can be toxic; hence, we aimed to determine markers of response to afatinib in order to assess prognosis. Patients and Methods: Information on clinical background, therapeutic effects, and adverse events was collected retrospectively at one Institution from patients treated with afatinib as initial epidermal growth factor receptor (EGFR)tyrosine kinase inhibitor (TKI). We examined the relationship between different adverse events and their effects on prognosis. Results: Afatinib was used in 32 patients as the initial EGFR-TKI. Adverse events of grade 3 or higher including diarrhoea (12.5\%), paronychia (6.3\%), and stomatitis (3.1\%) were experienced by patients. The median progression-free survival (PFS) was 15.4 months. A relationship between skin rash severity and PFS was observed. Conclusion: Grade 2 or higher skin rash might be a marker for long-term efficacy of afatinib when administered as a first-line treatment.
\end{abstract}

Epidermal growth factor receptor (EGFR) tyrosine kinase inhibitors (TKIs) are standard treatment for patients with $E G F R$ mutation-positive advanced non-small-cell lung cancer (NSCLC). Afatinib, a second-generation EGFR-TKI, is an irreversible blocker of the ErbB family of receptors that covalently binds to the tyrosine kinase domain of EGFR (1). Afatinib was reported to significantly improve overall survival (OS) in patients with EGFR exon 19 deletions compared to chemotherapy in the combined analyses of the LUX-Lung 3 and LUX-Lung 6 trials (2). In the LUX-Lung

Correspondence to: Shingo Nasu, MD, Department of Thoracic Oncology, Osaka Prefectural Hospital Organization Osaka Habikino Medical Center, 3-7-1 Habikino, Habikino City, Osaka, 583-8588, Japan. Tel: +81 729572121, Fax: +81 729578002, e-mail: hugurahoma@yahoo.co.jp

Key Words: Afatinib, EGFR-tyrosine kinase inhibitor, treatmentnaïve patients, non-small cell lung cancer, skin rash.
7 trial, the progression-free survival (PFS), time-to-treatment failure (TTF), and objective response rate were significantly improved with afatinib, although there was no significant difference in OS with afatinib versus gefitinib (3). On the other hand, frequent and severe adverse events (AEs), especially severe diarrhoea, nail effects, and rash/acne, have been reported (4). Although the efficacy of afatinib as a firstline treatment in patients with EGFR mutation-positive advanced NSCLC has been demonstrated, the management of AEs is important; hence, markers of response to afatinib are needed to assess prognosis. In clinical practice, there are insufficient data regarding the tolerability and efficacy of afatinib in EGFR-TKI-naïve patients with NSCLC harbouring EGFR mutations. To that end, we performed this retrospective study to investigate both the efficacy and AEs of afatinib specifically in this group of patients.

\section{Patients and Methods}

Study design and treatment. We retrospectively reviewed the medical records of 32 patients with EGFR mutation-positive NSCLC treated with the EGFR-TKI, afatinib, as a first-line medication at our Institute between May 2014 and April 2016. Patient clinical backgrounds, therapeutic outcomes, AEs, and prognoses were investigated. This protocol was approved by the Medical Research Ethics Committee of Osaka Habikino Medical Center. The final observation date was September 30, 2017.

Performance status (PS) was estimated according to the Eastern Cooperative Oncology Group (ECOG) classification (5). Therapeutic effects were evaluated using the Response Evaluation Criteria in Solid Tumours version 1.1 (6). Toxicities associated with afatinib treatment were graded according to the Common Terminology Criteria for Adverse Events (CTCAE), version 4.0 (7). Afatinib administration was discontinued when disease progression or intolerable toxicity was observed.

Management of AEs. Thoracic oncologists cooperated with the Japanese Society of Pharmaceutical Health Care and Sciencescertified oncology pharmacists, a certified nurse specialist in cancer nursing, two certified nurses in palliative care, and a certified nurse in cancer chemotherapy nursing to manage the AEs. A clinical management pathway designed at our Institution was used during 
hospitalization for the administration of treatment, while an outpatient nurse and outpatient pharmacist supervised the outpatient clinic (8). We defined diarrhoea as stool types 6 and 7 according to the Bristol Stool Form Scale, and loperamide was orally administered as necessary (9). For rash management, heparinoid was applied twice a day, while minocycline $(100 \mathrm{mg})$ was routinely administered prophylactically. When rashes appeared, steroidal antiinflammatory agents were administered immediately.

Outcome parameters and statistical analyses. The outcome parameters measured in this study were PFS and OS. PFS was calculated as the duration between the start of treatment and progression or death. OS was measured from the date of diagnosis (or confirmed recurrence in postoperative cases) to the date of death. PFS and OS were assessed by using Kaplan-Meier analysis, and comparisons between treatment arms were performed using a log-rank test. $p$-Values less than 0.05 were considered significant. Univariate and multivariate analyses were performed using the Cox proportional hazards and logistic regression models. All statistical analyses were performed using $\mathrm{R}$ software (version 2.13.1; EZR Development Core Team 2011, R: a language and environment for statistical computing, Foundation for Statistical Computing; Vienna, Austria).

\section{Results}

Patients. Thirty-two patients were treated with afatinib during the study period, including 13 men and 19 women. The median patient age was 66 years (range $=39-83$ years). EGFR mutations including exon 19 deletion, L858R, and exon 19 deletion plus L858R were detected in 22, nine, and one case(s), respectively. Twenty-eight patients received no pre-treatment, while four received a cytotoxic anticancer drug (Table I).

Treatment. The starting dose was $40 \mathrm{mg}$ daily in 24 cases and $30 \mathrm{mg}$ daily in eight cases. Seven patients over 75 years old had their doses reduced to $30 \mathrm{mg}$ daily, while one patient with irritable bowel syndrome requested and received dose reduction to $30 \mathrm{mg}$ daily. The doses for 18 patients were reduced once or more because of diarrhoea, paronychia, fatigue, skin rash, nausea, and dry skin (Table II).

Efficacy. The overall response rate was $78.1 \%$.The median PFS was 15.4 months $[95 \%$ confidence interval $=11.5$ months-not attained (NA)]. The 1-year survival rate was 93.8\% (95\% confidence interval $=85.7-100 \%$ ), and median OS has not yet been reached (Figure 1). On univariate and multivariate analyses, factors significantly associated with good PFS included skin rash of grade 2 or higher and diarrhoea of grade 0 or grade 1 (Table III). No significant association was observed between the severity of paronychia or stomatitis and PFS. No significant differences in PFS were associated with starting dose and dose reduction.

Safety. The most common AEs experienced by the patients are shown in Table IV. Some of the patients displayed AEs
Table I. Patient demographics and clinical characteristics.

\begin{tabular}{lc}
\hline Category & Value \\
\hline Gender, $\mathrm{n}(\%)$ & \\
Male & $13(40.6 \%)$ \\
Female & $19(59.3 \%)$ \\
Median age (range), years & $66(39-83)$ \\
ECOG performance status & \\
0 & $4(12.5 \%)$ \\
1 & $24(75 \%)$ \\
2 & $3(9.4 \%)$ \\
3 & $1(3.1 \%)$ \\
Histopathology & $31(96.9 \%)$ \\
Adenocarcinoma & $1(3.1 \%)$ \\
Adenosquamous carcinoma & \\
Prior treatment & $28(87.5 \%)$ \\
None & $3(9.4 \%)$ \\
Platinum-doublet chemotherapy & $1(3.1 \%)$ \\
Docetaxel & \\
EGFR mutation & $22(68.8 \%)$ \\
Exon 19 deletion & $9(28.1 \%)$ \\
L858R & $1(3.1 \%)$ \\
Exon 19 + L858R &
\end{tabular}

ECOG, Eastern Cooperative Oncology Group; EGFR, epidermal growth factor receptor.

Table II. Dose and effect of afatinib.

\begin{tabular}{lc}
\hline Category & Number (\%) \\
\hline Starting dose & \\
$30 \mathrm{mg}$ & $8(25.0)$ \\
$40 \mathrm{mg}$ & $24(75.0)$ \\
Dose reduction & \\
Once & $9(28.1)$ \\
Two or more times & $9(28.1)$ \\
None & $14(43.8)$ \\
Best overall response & \\
Partial response & $25(78.1)$ \\
Stable disease & $6(18.8)$ \\
Not evaluable & $1(3.1)$ \\
Progressive disease & 0 \\
Reason for treatment failure & \\
Disease progression & $20(66.7)$ \\
Adverse event & $1(3.1)$ \\
\hline
\end{tabular}

of grade 3 and higher, including diarrhoea (12.5\%), paronychia (6.3\%), and stomatitis (3.1\%). Diarrhoea was the most frequent reason for reducing afatinib (12 patients), followed by paronychia (five patients), fatigue (three patients), skin problems/acne (two patients), and nausea and dry skin (one patient each). Only one patient (3.1\%) discontinued treatment due to drug-related AEs; this patient 
a

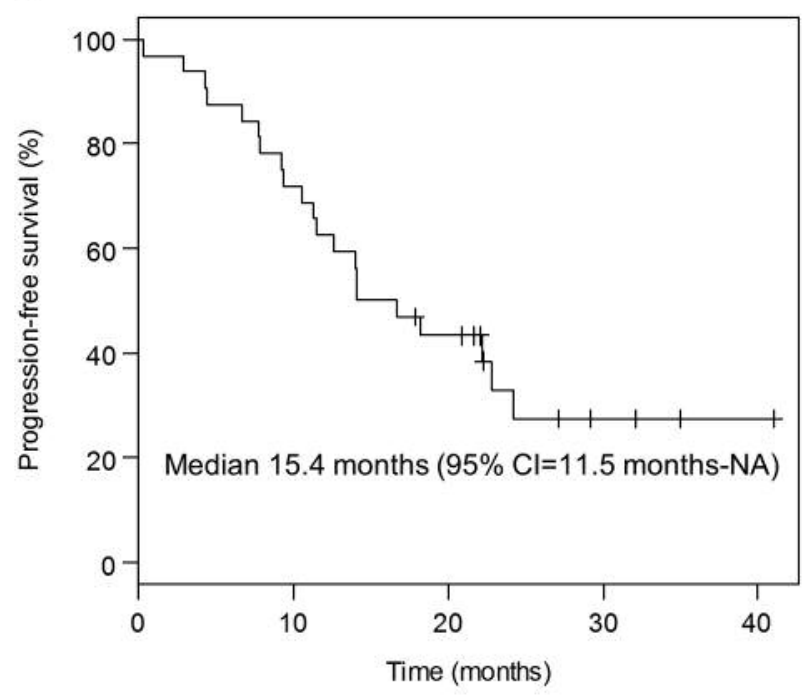

b

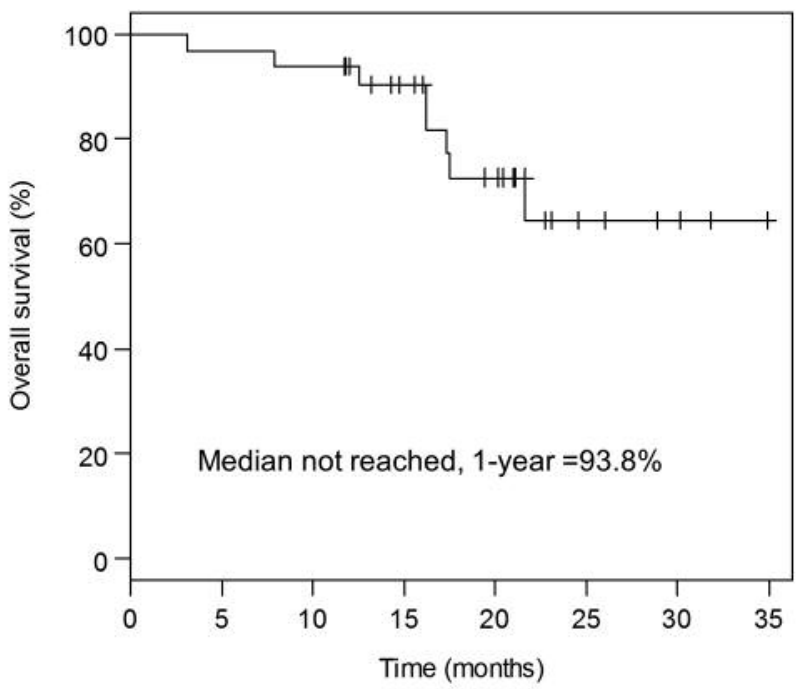

Figure 1. Progression-free survival rate (a), and overall survival rate $(b)$ in our cohort. NA: Not attained.

experienced grade 1 drug fever, which did not abate when the treatment was changed to erlotinib but subsided after the patient was treated with a platinum-based doublet. Taken together, long-term internal administration of afatinib was possible after reducing some patients' doses due to AEs. Following the eventual discontinuation of afatinib treatment in our study, 16 patients received subsequent anticancer therapy. Twelve patients received cytotoxic anticancer drugs. One patient received gefitinib, one patient received erlotinib, one received gefitinib plus bevacizumab, and one received nivolumab. Five patients did not receive subsequent anticancer therapy after afatinib; three patients developed carcinomatous meningitis, one patient developed brain metastasis, and one patient had a poor performance status. All patients received palliative care.

\section{Discussion}

In the present study, afatinib as a first-line EGFR-TKI was effective and safe. Furthermore, the severity of skin rash may be useful as a marker of afatinib efficacy. With respect to efficacy, median PFS was 15.4 months. In the LUX-Lung 7 trial, the median PFS was 11.0 months, whereas a subgroup analysis of the LUX-Lung 3 trial results (of Japanese patients receiving afatinib) revealed a median PFS of 13.8 months $(3,4)$. On univariate and multivariate analyses, a skin rash of grade 2 or higher and diarrhoea of grade 0 or 1 were significantly associated with good PFS. A previous analysis suggested that the severity of erlotinib-associated skin rash may be correlated with improved tumour response and

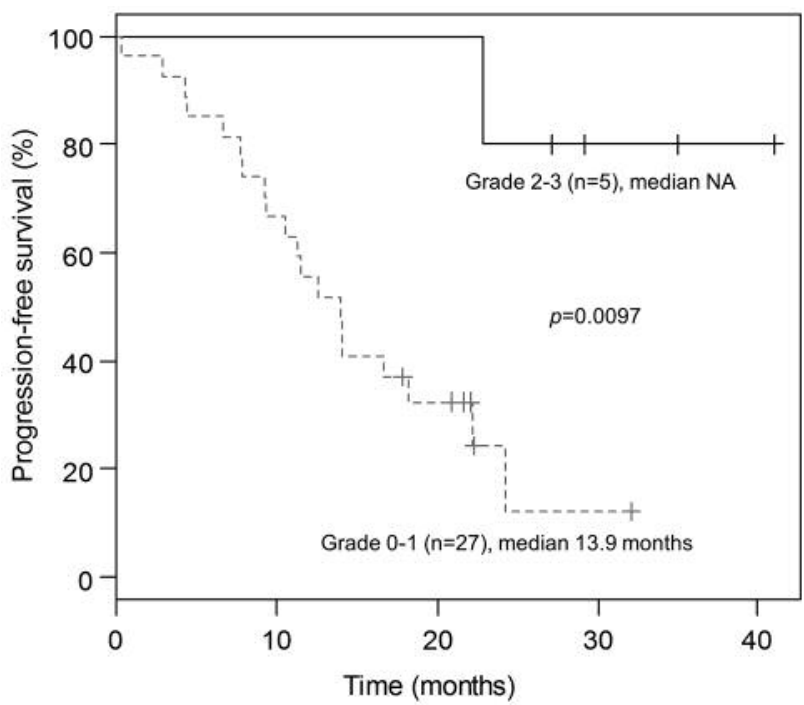

Figure 2. Progression-free survival rate for patients with non-small cell lung cancer with skin rash of grade 2 and higher versus those with grade 0 and 1. NA: Not attained.

survival in patients with EGFR mutation-positive NSCLC (10). Although minocycline was routinely administered prophylactically, prophylactic minocycline was not found to be associated with OS (11). For patients who develop a severe skin rash, the rash should be treated, and the medication continued as long as possible, even if a dose 
Table III. Prognostic factors associated with progression-free survival (PFS) as determined by univariate and multivariate analyses.

\begin{tabular}{|c|c|c|c|c|c|c|}
\hline \multirow[t]{2}{*}{ Factor } & \multirow[t]{2}{*}{$\mathrm{N}$} & \multirow{2}{*}{$\begin{array}{c}\text { Median PFS } \\
\text { (months) }\end{array}$} & \multicolumn{2}{|c|}{ Univariate analysis } & \multicolumn{2}{|c|}{ Multivariate analysis } \\
\hline & & & HR $(95 \% \mathrm{CI})$ & $p$-Value & $\mathrm{HR}(95 \% \mathrm{CI})$ & $p$-Value \\
\hline \multicolumn{7}{|l|}{ Gender } \\
\hline Male & 13 & 14.1 & & & & \\
\hline Female & 19 & 22.2 & $0.66(0.28-1.58)$ & 0.35 & & \\
\hline \multicolumn{7}{|l|}{ Age } \\
\hline$<75$ Years & 25 & 16.7 & & & & \\
\hline$\geq 75$ Years & 7 & 14.1 & $0.97(0.32-2.96)$ & 0.96 & & \\
\hline \multicolumn{7}{|l|}{$E G F R$} \\
\hline Deletion & 22 & 18.2 & & & & \\
\hline L858R & 9 & 9.3 & $1.85(0.74-4.66)$ & 0.18 & & \\
\hline \multicolumn{7}{|l|}{ Starting dose } \\
\hline $30 \mathrm{mg}$ & 8 & 12.7 & & & & \\
\hline $40 \mathrm{mg}$ & 24 & 17.5 & $0.98(0.89-1.09)$ & 0.73 & & \\
\hline \multicolumn{7}{|l|}{ Dose reduction } \\
\hline Once or more & 18 & 11 & & & & \\
\hline None & 14 & 10 & $1.73(0.73-4.13)$ & 0.21 & & \\
\hline \multicolumn{7}{|l|}{ Diarrhoea } \\
\hline Grade $0-1$ & 20 & NA & & & 1 & \\
\hline Grade 2-3 & 12 & 11.4 & $3.42(1.43-8.20)$ & 0.0034 & $2.88(1.20-6.94)$ & 0.018 \\
\hline \multicolumn{7}{|l|}{ Paronychia } \\
\hline Grade $0-1$ & 20 & 16.2 & & & & \\
\hline Grade $2-3$ & 12 & 14.1 & $1.39(0.58-3.31)$ & 0.46 & & \\
\hline \multicolumn{7}{|l|}{ Rash/acne } \\
\hline Grade $0-1$ & 27 & 13.9 & & & 1 & \\
\hline Grade $2-3$ & 5 & NA & $0.10(0.013-0.78)$ & 0.0097 & $0.12(0.016-0.98)$ & 0.047 \\
\hline \multicolumn{7}{|l|}{ Stomatitis } \\
\hline Grade $0-1$ & 28 & 14.0 & & & & \\
\hline Grade $2-3$ & 4 & 24.3 & $0.52(0.12-2.23)$ & 0.37 & & \\
\hline
\end{tabular}

CI: Confidence interval; HR: hazard ratio; EGFR, epidermal growth factor receptor.

reduction is required. The Phase III FLAURA trial showed a significant and clinically meaningful PFS benefit with osimertinib compared to current first-line standard-of-care treatment (erlotinib or gefitinib), with a median PFS of 18.9 months (12). Despite the small number of cases in the present study, the PFS of all cases with grade 2 or higher skin rash was longer than that previously reported (12). With respect to diarrhoea as an adverse event, the relationship between the mild diarrhoea and good PFS was not clear. When diarrhoea developed, loperamide was orally administered immediately until the diarrhoea resolved. Because the severity of diarrhoea in CTCAE version 4.0 is defined as the number of stools passed within a period of time, severe grade diarrhoea might decrease due to loperamide. The doses in seven patients over 75 years old were reduced to $30 \mathrm{mg}$ daily; no significant differences in PFS was observed between the patients who commenced treatment with doses of $30 \mathrm{mg}$ daily and those who started at $40 \mathrm{mg}$ daily. It has been reported that a low starting dosage of afatinib might enable elderly patients or those with
Table IV. Treatment-related adverse events.

\begin{tabular}{lcccc}
\hline Adverse event & $\begin{array}{c}\text { Any grade } \\
(\%)\end{array}$ & $\begin{array}{c}\text { Grade } 1 \\
(\%)\end{array}$ & $\begin{array}{c}\text { Grade 2 } \\
(\%)\end{array}$ & $\begin{array}{c}\text { Grade 3 } \\
(\%)\end{array}$ \\
\hline Diarrhoea & $31(96.9)$ & $19(59.4)$ & $8(25.0)$ & $4(12.5)$ \\
Paronychia & $27(84.4)$ & $15(46.9)$ & $10(31.3)$ & $2(6.3)$ \\
Rash/acne & $26(81.3)$ & $21(65.6)$ & $5(15.6)$ & 0 \\
Stomatitis & $25(78.1)$ & $21(65.6)$ & $3(9.4)$ & $1(3.1)$ \\
Dysgeusia & $12(37.5)$ & $12(37.5)$ & 0 & 0 \\
Fatigue & $11(34.4)$ & $7(21.9)$ & $4(12.5)$ & 0 \\
Dry skin & $11(34.4)$ & $10(31.3)$ & $1(3.1)$ & 0 \\
Anorexia & $7(21.9)$ & $7(21.9)$ & 0 & 0 \\
Pruritus & $6(18.8)$ & $6(18.8)$ & 0 & 0 \\
Nausea & $4(12.5)$ & $4(12.5)$ & 0 & 0 \\
\hline
\end{tabular}

low PS with advanced refractory NSCLC to receive this drug as salvage therapy (13). Therefore, it was suggested that reducing the starting dose according to age does not 
significantly affect the therapeutic efficacy. Although 18 patients $(56 \%)$ experienced dose reductions after commencing treatment, dose reduction did not negatively influence PFS in our study. This is consistent with a posthoc analysis of the randomized LUX-Lung 3 and 6 trials, which showed that dose reduction had no significant effect on PFS (14). After discontinuing afatinib, systemic anticancer therapy was most frequently employed, whereas third-generation EGFR-TKIs were not used. This was not only because third-generation EGFR-TKIs were not yet available for clinical use at the time progressive disease was detected, but also because the frequency of T790M mutations was low. Only three out of 15 patients were T790M mutation-positive, which is a smaller proportion than in a previous study where the frequency was $50 \%$ (15). With respect to safety, some patients displayed AEs of grade 3 or higher, including diarrhoea $(12.5 \%)$, paronychia $(6.3 \%)$, and stomatitis $(3.1 \%)$. AEs of grade 3 or higher were less frequent compared to those that occurred according to a subgroup analysis of the LUX-Lung 3 trial patients in Japan (4). The rate of treatment discontinuation due to drug-related AEs was low (3.1\%).

In our study, because palliative care intervention by a medical care team was performed early, this allowed for the early detection and treatment of side-effects, in addition to preventing some of these side-effects altogether. Temel et al. reported that among patients with metastatic NSCLC, early palliative care led to significant improvements in the quality of life and OS (16).

Our study had limitations. Firstly, we retrospectively analyzed data from a single institution, and our sample size was small. Secondly, the number of patients with EGFR exon 19 deletions was relatively higher than that of patients with L858R mutation, which may have skewed our data towards better PFS and OS findings.

Introducing afatinib as a first-line EGFR-TKI is safe and effective for treating patients with EGFR mutation-positive NSCLC in clinical practice. Moreover, skin rash of grade 2 or higher can be a useful marker of afatinib efficacy. It is important for patients with a severe skin rash to continue afatinib as long as possible through early treatment or dose reduction.

\section{Conflicts of Interest}

The Authors have no conflicts of interest in regard to this study.

\section{References}

1 Solca F, Dahl G, Zoephel A, Bader G, Sanderson M, Klein C, Kraemer O, Himmelsbach F, Haaksma E and Adolf GR: Target binding properties and cellular activity of afatinib (BIBW 2992), an irreversible ErbB family blocker. J Pharmacol Exp Ther 343: 342-350, 2012.
2 Yang JC, Wu YL, Schuler M, Sebastian M, Popat S, Yamamoto N, Zhou C, Hu CP, O’Byrne K, Feng J, Lu S, Huang Y, Geater SL, Lee KY, Tsai CM, Gorbunova V, Hirsh V, Bennouna J, Orlov S, Mok T, Boyer M, Su WC, Lee KH, Kato T, Massey D, Shahidi M, Zazulina V and Sequist LV: Afatinib versus cisplatinbased chemotherapy for EGFR mutation-positive lung adenocarcinoma (LUX-Lung 3 and LUX-Lung 6): analysis of overall survival data from two randomised, phase 3 trials. Lancet Oncol 16: 141-151, 2015.

3 Park K, Tan EH, O’Byrne K, Zhang L, Boyer M, Mok T, Hirsh V, Yang JC, Lee KH, Lu S, Shi Y, Kim SW, Laskin J, Kim DW, Arvis CD, Kölbeck K, Laurie SA, Tsai CM, Shahidi M, Kim M, Massey D, Zazulina V and Paz-Ares L: Afatinib versus gefitinib as first-line treatment of patients with EGFR mutation-positive non-small-cell lung cancer (LUX-Lung 7): a phase 2B, open-label, randomised controlled trial. Lancet Oncol 17: 577-589, 2016.

4 Kato T, Yoshioka H, Okamoto I, Yokoyama A, Hida T, Seto T, Kiura K, Massey D, Seki Y and Yamamoto N: Afatinib versus cisplatin plus pemetrexed in Japanese patients with advanced non-small cell lung cancer harboring activating EGFR mutations: Subgroup analysis of LUX-Lung 3. Cancer Sci 106: 1202-1211, 2015.

5 Oken MM, Creech RH, Tormey DC, Horton J, Davis TE, McFadden ET and Carbone PP: Toxicity and response criteria of the Eastern Cooperative Oncology Group. Am J Clin Oncol 5: 649-655, 1982.

6 Eisenhauer EA, Therasse P, Bogaerts J, Schwartz LH, Sargent D, Ford R, Dancey J, Arbuck S, Gwyther S, Mooney M, Rubinstein L, Shankar L, Dodd L, Kaplan R, Lacombe D and Verweij J: New response evaluation criteria in solid tumours: revised RECIST guideline (version 1.1). Eur J Cancer 45: 228247, 2009.

7 Common Terminology Criteria for Adverse Events (CTCAE). Version 4.0. Published: May 28, 2009 (v4.03: June 14, 2010). U.S. Department of Health and Human Services. National Institutes of Health, National Cancer Institute.

8 Iwata K, Ryota N, Hikita A, Sando M, Suzuki H, Tamiya M, Azuma Y, Tani E, Hamaguchi M, Tanaka A, Shiroyama T, Morishita N, Okamoto N, Futagami $\mathrm{S}$ and Hirashima T: Retrospective analysis of the afatinib clinical pathway during the 28-day introductory period-The Japanese Style of Collaborative Drug Therapy Management (J-CDTM). Gan To Kagaku Ryoho 42: 967-972, 2015.

9 Lewis SJ and Heaton KW: Stool form scale as a useful guide to intestinal transit time. Scand J Gastroenterol 32: 920-924, 1997.

10 Wacker B, Nagrani T, Weinberg J, Witt K, Clark G and Cagnoni PJ: Correlation between development of rash and efficacy in patients treated with the epidermal growth factor receptor tyrosine kinase inhibitor erlotinib in two large phase III studies. Clin Cancer Res 13: 3913-3921, 2007.

11 Melosky B, Anderson H, Burkes RL, Chu Q, Hao D, Ho V, Ho C, Lam W, Lee CW, Leighl NB, Murray N, Sun S, Winston R and Laskin JJ: Pan Canadian Rash Trial: A randomized phase III trial evaluating the impact of a prophylactic skin treatment regimen on epidermal growth factor receptor-tyrosine kinase inhibitor-induced skin toxicities in patients with metastatic lung cancer. J Clin Oncol 34: 810-815, 2016.

12 Ramalingam S, Reungwetwattana T, Chewaskulyong B, Dechaphunkul A, Lee KH, Imamura F, Nogami N, Ohe Y, Cheng Y, Cho BC, Cho EK, Vansteenkiste J, Voon PJ, Zhou C, Gray 
JE, Hodge R, Rukazenkov Y and Soria JC: Osimertinib vs. standard of care (SoC) EGFR-TKI as first-line therapy in patients (pts) with EGFRm advanced NSCLC: FLAURA ESMO 28(Suppl 5): 1093, 2017.

13 Kashiwabara K, Semba H, Fujii S and Tsumura S: Tolerability and efficacy of afatinib at a low starting dosage in 10 elderly or low performance status patients with advanced refractory nonsmall-cell lung cancer. Respir Investig 54: 468-472, 2016.

14 Yang JC, Sequist LV, Zhou C, Schuler M, Geater SL, Mok T, Hu CP, Yamamoto N, Feng J, O’Byrne K, Lu S, Hirsh V, Huang Y, Sebastian M, Okamoto I, Dickgreber N, Shah R, Märten A, Massey D, Wind S and Wu YL: Effect of dose adjustment on the safety and efficacy of afatinib for EGFR mutation-positive lung adenocarcinoma: post hoc analyses of the randomized LUXLung 3 and 6 trials. Ann Oncol 27: 2103-2110, 2016.
15 Wu SG, Liu YN, Tsai MF, Chang YL, Yu CJ, Yang PC, Yang JC, Wen YF and Shih JY: The mechanism of acquired resistance to irreversible EGFR tyrosine kinase inhibitor-afatinib in lung adenocarcinoma patients. Oncotarget 7: 12404-12413, 2016.

16 Temel JS, Greer JA, Muzikansky A, Gallagher ER, Admane S, Jackson VA, Dahlin CM, Blinderman CD, Jacobsen J, Pirl WF, Billings JA and Lynch TJ: Early palliative care for patients with metastatic non-small-cell lung cancer. N Engl J Med 363: 733742, 2010.

Received December 17, 2017

Revised January 18, 2018

Accepted January 24, 2018 